\title{
EFL Teachers' Challenges in Maximizing Classroom Interaction
}

\author{
Trinh Quoc Lap ${ }^{1 *} \&$ Huynh Vuong Uyen Thy ${ }^{2}$ \\ ${ }^{1}$ Can Tho University, Viet Nam \\ ${ }^{2}$ Kien Giang University, Viet Nam \\ *Trinh Quoc Lap, E-mail: tqlap@ctu.edu.vn
}

Received: October 31, 2017 Accepted: November 4, 2017 Online Published: November 8, 2017

doi:10.22158/selt.v5n4p695 URL: http://dx.doi.org/10.22158/selt.v5n4p695

\begin{abstract}
Classroom interaction plays a significant role in facilitating learners' development of communicative competence by making input more comprehensible to learners and maximizing the language input to become learners' intake (Krashen, 1987; Swain, 1995; Long, 1996; Gass, 1997; Lucha \& Berhanu, 2015). Results of related studies reveal a low level of communicative competence of many Vietnamese learners of English, which could result from the lack of opportunities for interaction in Vietnamese EFL classes (Hiep, 2007; Ngoc, 2010; Canh, 2011; Ngan, 2013; Tuyen, 2013; Duy, 2014). This study aims to investigate EFL teachers' challenges in maximizing classroom interaction. A questionnaire was administered to 50 lecturers from sixteen colleges and universities in the Mekong Delta of Viet Nam to examine their challenges in maximizing classroom interaction. The results of the study show that Vietnamese EFL lecturers encountered challenges related to physical factors or learning conditions, learners'factors and teachers' factors as well. Learner-related factors showed to be most significant challenge in this study.
\end{abstract}

Keywords

EFL teachers' challenges, classroom interaction, ELT in the Mekong Delta

\section{Introduction}

Classroom interaction plays a significant role in fostering learner's development of communicative competence. Classroom interaction makes input more comprehensible to learners and maximizes the input to be learners' intake (Krashen, 1985; Swain, 1995; Long, 1996; Gass, 1997; Lucha \& Berhanu, 2015). Without interaction, input could not be taken in, resulting in no output produced. As can be seen, a strong connection between opportunities for classroom interaction and learners' development of communicative competence is realized. However, maximizing interaction in EFL classrooms is somehow challenging for many Vietnamese teachers. Bygate (1987) claimed that EFL teachers find it challenging to maximize the interaction with learners and among learners though they acknowledge the value interaction brings into their classrooms. As a result, learners are not able to communicate 
effectively in the target language after years learning it (Bygate, 1987). Results of relevant studies in the Vietnamese context show a low level of communicative competence of a majority of Vietnamese learners of English (Hiep, 2007; Ngoc, 2010; Canh, 2011; Ngan, 2013; Tuyen, 2013; Duy, 2014). Why Vietnamese learners of English are not strong at using English could be explained in terms of their lack of opportunities for interaction in English classes. In other words, opportunities for classroom interaction have not been maximized efficiently in Vietnamese EFL classes resulting in a low level of communicative competence. What challenges in maximizing classroom interaction were encountered by Vietnamese EFL teachers in the Mekong Delta interested the researchers of this study.

\section{Literature Review}

\subsection{Classroom Interaction}

Varied definitions of Classroom Interaction (CI) were abound in available literature. Lucha and Berhanu (2015) defined CI as a collaborative process of exchanging ideas, opinions or emotion among members in the classroom. Brown (2000) and Rivers (1987) ever argued that interaction is the collaborative exchange of thoughts, feelings, or ideas between two or more people. These exchanges lead to reciprocal effects. Ellis (1991) emphasized that CI is all communication including teacher-students exchanges and all formal drills within the classroom. Whereas $\mathrm{CI}$ is defined as a process of negotiating communication problems between communicators (Long, 1996; Kumaravadivelu, 2003), it is seen as a behavior by Simpson and Galbo (1986). Tsui (2001) viewed CI in light of input, interaction and output. Input refers to teachers' talk (i.e., teachers' questions and feedback). Output refers to the language performed by EFL learners. Interaction refers to the relationship between input and output which shapes the classroom interaction. According to Robison (1994), CI is a face-to-face action which could be verbal or non-verbal.

From different authors' view of interaction, it could be deduced that interaction requires two-sided involvement of at least two individuals. Interaction is a give-and-take of information or an exchange of messages among interlocutors. In the scope of this study, classroom interaction is considered a reciprocal process of negotiating of meanings and exchanging feedback among communicators - the teacher and learners and among the learners - within the classroom.

\subsection{Features of Classroom Interaction}

From the working definition of CI by the researchers of this study, it is obvious that CI comprises two main features: negotiation of meanings and feedback exchange that should be present in success in learning a language. According to Ellis and Foto (1999) and Gass (1997), learners would benefit from the exposure to negative evidence through CI in which they have opportunities for testing their hypothesis and modifying their output. In this light, CI provides learners with opportunities for negotiation of meanings and feedback exchange.

\subsubsection{Negotiation of Meanings}

Negotiation of meanings is the process of verbal exchanges among interlocutors to keep the 
communication on-going (Ellis \& Barkhuizen, 2005). In order to avoid communication breakdown due to speakers' scarcity of vocabulary and structures, every speaker needs to modify their utterances to make their output comprehensible to their counterparts. The process of modification of output may include different techniques for repairing interaction in classroom communication. Mackey (2007) suggested repetition, segmentation, rewording and more time allowance as measures to promote classroom interaction.

\subsubsection{Feedback Exchange}

It is evidenced that the inter-language of EFL learners includes a numbers of mistakes. CI, therefore, provides learners with opportunities to exchange feedback and create demands on adjusting their inter-language. Classroom interaction with feedback could facilitate the learning and direct learners' attention to the mistakes in their inter-language. Feedback may be provided by the teacher or more capable learners in explicit or implicit ways.

\subsection{Types of Classroom Interaction}

CI has been clustered differently by different researchers in the field. Moore (1989) classified CI into three main types which in turn are explained as follows.

Learner-content interaction: The interaction occurs when learners encounter reading materials related to the target subject matter. In order to maximize learner-content interaction, learners need to be provided with various accessible sources of learning materials. Specifically, they should get adequately exposed to English environments in which they might read and listen in English. Sources of information related to English subject matter need to be comprehensible to EFL learners. Then, there could be challenges in maximizing this type of classroom interaction, the interaction between EFL learners and the target language itself.

Teacher-learner interaction: The interaction occurs when the instructors attempt to present subject contents, motivate, evaluate, and even provide affective support to learners. The process of negotiating the subject contents in each lesson requires EFL teachers' not only sufficient knowledge of the subject matter but also special pedagogical qualifications. EFL teachers should be able to apply different teaching techniques or activities to achieve their teaching purposes. These techniques or activities would be affected by different factors including the teachers' language and professional competences and learners' language competence. Some other factors such as seat arrangement, class size, cultural norms or psychological factors also play a role in affecting the interaction between learners and their teachers.

Learner-learner interaction: This type of interaction includes that of learner and a peer or learner and a group or the learner herself. The two most powerful factors facilitating language learning in EFL classes are teacher-learner and learner-learner interaction. As a result, in this current study, the researcher focused on investigating the challenges in maximizing the two main types of $\mathrm{CI}$ : teacher-learner interaction and learner-learner interaction. 


\subsection{The Role of Classroom Interaction in Language Teaching and Learning}

The two main features of CI, negotiation of meanings and feedback exchange, are evidences of the presence of language acquisition. CI plays an essential role in learners' development of communicative competence due to opportunities learners receive to negotiate meanings and to exchange feedback (Ellis, 2005; Kumaravadivelou, 2003; Brown, 2001; Vrasidas, 2000; Gass, 1997; Long, 1996; Ellis, 1991; Moore, 1989; Simpson \& Galbo, 1986; Vygotsky, 1978; Dewey, 1938). Through CI between learners and their counterparts, both negotiation of meanings and exchanges of feedback on their peers' unacceptable inter-language were taken place. Gass (1997) asserted that raising awareness of the negative evidence of learners' inter-language during interaction would benefit the development of their communicative competence.

Vygotsky (1978) explained the crucial role of social interaction for learners' psychological development through his theory of Zone of Proximal Development (ZPD). The ZPD theory, which centers on the development of learners' independence in solving problems, has an important pedagogical implication for language learning and teaching. Interacting with people at higher level of English proficiency could foster the development of learners' ability in English performance. CI is, therefore, a key factor that facilitates learners' development of communicative competence (Vygotsky, 1978; Ellis, 1991; Brown, 2001).

Vrasidas (2000) acknowledged that interaction is an essential component of language learning process and Kumaravadivelou (2003) argued that teachers can maximize learning opportunities in classes by involving learners in meaningful communication. As can be seen, learners' class participation in meaningful communication can facilitate second language acquisition. From all what was presented, for learning to occur, learners should get involved in $\mathrm{CI}$ and be provided with opportunities for taking risks in testing hypotheses of their inter-language.

In light of language teaching principles proposed by Ellis (2005) and Brown (2001), CI plays an essential role in facilitating learning process. CI offers learners opportunities to produce output and make the classroom an input-full environment. Thanks to teacher-learner interaction and learners-learner interaction, one's output becomes their peers' input. This results in learners' development of their communicative competence.

\subsection{Factors Affecting Learners' Class Participation}

With regard to the essential role of classroom interaction in language acquisition, several studies on factors affecting learners' participation in class conducted.

Smith (1992) proposed five influential factors affecting learners' class participation. Those are class size, lack of rewards, anxious feeling, intimidated feeling, and scared feeling, which could be classified into three themes including learning conditions, teacher-related factors and learner-related factors. Table 1 below summarizes the factors affecting learners' class participation suggested by Smith (1992). 
Table 1. Factors Affecting Learners' Class Participation (Smith, 1992)

\begin{tabular}{ll} 
Themes & Factors \\
\hline Learning conditions & Class size \\
Teacher-related factors & Lack of rewards \\
Learner-related factors & Feeling anxious \\
& Feeling intimidated \\
& Being afraid \\
\hline
\end{tabular}

Berdine (1986) proposed seventeen factors influencing learners' class participation which could be also categorized into the three similar themes as the factors proposed by Smith (1992). Table 2 below describes seven factors in three clusters: learning conditions, teacher-related factors, and learner-related factors.

Table 2. Seventeen Factors Affecting Learners' Class Participation

\begin{tabular}{ll}
\hline Themes & Factors \\
\hline Learning conditions & Class size \\
& Time of day \\
& Temperature of room \\
& Length of class \\
& Types of participation \\
Teacher-related factors & Boring or bored \\
& Pushy \\
& Moody \\
& Close-minded \\
Too opinionated \\
Condescending \\
Unfriendly \\
Not getting adequate sleep \\
Inexperienced \\
Immature \\
Being the minority within the class \\
\hline
\end{tabular}

An important component of $\mathrm{CI}$ is teacher's questions. The complexity of the questions asked by the teacher decides the number of responses from the learners. In other words, the complexity of teacher's questions is considered an influential factor affecting teacher-learner interaction (Tsui, 2001). The researcher also proposed some other factors affecting classroom interaction including the offering of 
wait-time for processing and preparation for responses, the types of task and the required number of participants for each task. Concerning learner-related factors affecting classroom interaction, Tsui (2001) indicated the following factors: language proficiency, learning styles, and cultural norms. Table 3 below summarizes the factors mentioned by Tsui (2001).

Table 3. Factors Affecting Learners' Class Participation (Tsui, 2001)

\begin{tabular}{ll}
\hline Themes & Factors \\
\hline Learning conditions & Types of task \\
& Number of members for each collaborative task \\
& Wait-time for preparation \\
Teacher-related factors & Teacher's questions \\
Learner-related factors & Language proficiency \\
& Learning styles \\
& Cultural norms \\
\hline
\end{tabular}

Factors related to participants' background information such as gender, age, teaching experience and academic qualifications appear to have some influence on their frequency of encountering challenging in maximizing classroom interaction (Fassinger, 1995).

\subsection{Related Studies}

A number of challenges in maximizing classroom interaction due to teacher-related factors and learning conditions were explored by Saeed, Khaksari, Eng and Ghani, (2016). Lucha and Berhanu (2015), Suryati (2015) and Toni and Parse (2013).

Saeed, Khaksari, Eng and Ghani (2016) conducted a study on the role of learner-learner interaction in the development of speaking skills. 52 international postgraduate students of an intensive English class at Language Centre at Universiti Utara Malaysia (UUM) participated in the study after receiving unsuccessful results of the university's entrance test of English. The researchers followed a quantitative research approach, using a questionnaire to investigate learners' perception about the role of learner-learner interaction in developing learners' speaking performance. Two pre- and post- speaking tests were also employed to collect data about the learners' improvement of their speaking performance after finishing the English course using communicative teaching approach. The results show that learners' speaking performance was enhanced significantly and learner-learner interaction played a crucial role in improving the learners' speaking ability.

Lucha and Berhanu (2015) investigated the oral interaction among students in EFL speaking classroom. 182 EFL secondary students and five teachers were recruited to participate in the study. Three different research instruments, namely, classroom observation, questionnaire and interview were employed. The results show that there were several challenges in implementing oral interaction in EFL speaking 
classrooms at secondary schools. The students did not have enough opportunities to interact or negotiate meanings during their learning which resulted in a mismatch between the learners' English performance and the expected level of their English proficiency. In addition, the teachers' lack of time-devotion and professional support for students' interaction is one of the challenges indicated in the study. Moreover, having big-sized classes also resulted in the limitation of oral interaction. It becomes clear that teachers and learners encountered challenges in oral interaction in EFL classrooms. Therefore, learners were unprepared for interactive target language use. The researcher also advocated the significance of interaction in speaking classes. He suggested that learners should have opportunities to sufficiently listen to and read authentic dialogues or input so that their speaking performance could be increased.

Suryati (2015) studied the implementation of interaction strategies in English teaching practice of eighteen teachers from lower secondary schools in Malang. In order to explore the most frequently used interaction strategies of the eighteen teachers, observations of their thirty lessons were conducted to collect data. The Self Evaluation Teacher Talk (SETT) was adopted as an observation instrument. After observing each teacher's lesson once or twice, the researcher reviewed her observation notes and transcribed video records so that she could identify the teachers' time-spending on classroom interaction and the most frequently used interaction strategies. The findings show that there was a shortage of time devoting to classroom interaction and the most frequently used interaction strategies were Initiation-Response-Feedback (IRF) patterns, display questions, teacher echo and extended teacher's turns.

Toni and Parse (2013) conducted a descriptive study in a language institute in Tehran aiming to investigate classroom interaction in terms of teachers' questioning techniques. The data were collected from a class of six lower-intermediate English learners by randomly tape recording three 45-minute lessons to interpret the teacher-learner interaction focusing on the questioning-responding process. The teacher, one of the researchers, attempted to make the classroom interaction as natural as possible so that he could find out what techniques of questioning could be used to encourage learners to participate in classroom interaction. The results show that inferential questions, which made up $27 \%$ of the teacher's total number of 322 questions, were most frequently employed by the teacher to engage learners in classroom interaction.

In summary, the challenges caused by teachers' factors included teachers' lack of awareness of the significance of free interaction or negotiation in language learning and lack of time-devoting and professional support while having big-sized classes was one noticeable challenge related to learning conditions found out by Lucha and Berhanu (2015). The researchers suggested expanding learners' exposure to authentic input to improve their speaking performance. Suryati (2015) also claimed that teachers' scarcity of time-spending on classroom interaction is one significant challenge in maximizing the interaction in EFL classes. The researcher also proposed several strategies for employing interaction in EFL classes such as using display questions, IRF, teacher echo, and extended teachers' turn. The 
suggestion on using display questions was inconsistent to results of the study conducted by Toni and Parse (2013) which reveals the greatest frequency of inferential questions employed by EFL teachers to maximize the interaction in EFL classes.

\section{Method}

3.1 Design

A descriptive design and quantitative research method were used in this study to explore EFL teachers' challenges in maximizing the classroom interaction. The researchers attempt to answer three research questions:

a) To which extend do EFL teachers encounter challenges in maximizing classroom interaction?

b) What challenges in maximizing classroom interaction are encountered by EFL teachers?

c) What challenges in maximizing classroom interaction are most frequently encountered by EFL teachers?

\subsection{Participants}

The sample of this study comprises 50 EFL lecturers from 16 universities and colleges in 8 cities and provinces of the Mekong Delta of Viet Nam. Convenient sampling technique was employed to recruit the approachable and eligible participants for the study. The participants are varied in terms of their backgrounds, teaching experience, age ranges, gender and academic qualifications.

\subsection{Instrument: The Questionnaire}

Questionnaire is believed to be a practical research instrument enabling researchers to quickly collect a large amount of quantitative data in a relatively cost effective way (Sapsford \& Jupp, 2006; Ackroyd, 1992). In this study, a questionnaire was expected to enable the researcher to collect quantitative data about the frequency of encountering each challenge in maximizing classroom interaction. In order to gain the quantitative data, the questionnaire employed the five-likert scale of frequency, namely (1) never, (2) seldom, (3) sometimes, (4) often and (5) always.

There are two main sections in the questionnaire. The first section of the questionnaire comprises 33 statements of challenges in maximizing classroom interaction and one open-ended question on other challenges encountered by the EFL teachers. The questionnaire was originally designed with three clusters including 34 items. The 34 items of three clusters were mixed up in one table of piloting questionnaire. After piloting the questionnaire, one item was deleted due to its too low score of reliability. The remaining 33 items were re-categorized into three clusters and re-worded based on the piloting results.

The first cluster consists of 10 challenges related to physical factors or learning conditions. This cluster aims to collect data on the frequency of encountering challenges in maximizing classroom interaction caused by physical factors or learning conditions. The second cluster comprises 12 challenges related to learner-related factors. The third cluster includes 11 challenges related to EFL teacher-related factors. The 33 statements of EFL challenges in maximizing classroom interaction are based on the factors 
affecting learners' class participation proposed by Tsui (2001), Smith (1992), and Berdine (1986). In addition to the fixed statements of challenges in maximizing classroom interaction, the open-ended question inserted at the end of the questionnaire could provide an opportunity for the respondents to express further information about challenges in maximizing classroom interaction. Table 4 below summarizes the content of the three clusters of challenges of the questionnaire.

Table 4. Summary of Items for Each Cluster in the Questionnaire

\begin{tabular}{ll}
\hline Content & Items \\
\hline Cluster 1: Challenges related to physical factors and learning conditions (10 items). & $1,2,3,4,5$, \\
+ Classroom facilities & $6,7,8,9$, \\
+ Seat arrangement & 10 \\
+ Learning material & \\
+ Time allowance for each lesson & \\
+ Class size & $11,12,13$, \\
Cluster 2: Challenges related to learner-related factors (12 items). & $14,15,16$, \\
+ Learners' confidence & $17,20,21$, \\
+ Learners' English proficiency & 22 \\
+ Learners' learning motivation & \\
+ Learners' learning styles & \\
+ Learners' collaboration skills & \\
+ Learners' personality & \\
Cluster 3: Challenges related to teacher-related factors (11 items). & $23,24,25$, \\
+ Teachers' personality & $26,27,28$, \\
+ Teachers' time devotion to lesson preparation & $29,30,31$, \\
+ Teachers' instructions and questioning techniques & 32,33 \\
+ Teachers' attitudes towards employing ICT in classroom & \\
+ Teachers' favorite teaching methods & \\
+ Teachers' professional competence & \\
\hline
\end{tabular}

The second section of the questionnaire aims to collect some background information of the participants on their age range, gender, teaching experience and academic qualifications which are believed to influence the EFL teachers' frequency of encountering challenges in maximizing classroom interaction (Fassinger, 1995). 


\section{Results and Discussion}

\subsection{Participants' Frequency of Encountering Challenges in Maximizing Classroom Interaction}

The data on the participants' frequency level of encountering challenges in maximizing classroom interaction consists of 33 items classified into three clusters, (1) challenges related to physical factors or learning conditions, (2) challenges related to learner-related factors and (3) challenges related to teacher-related factors. The reliability of the items is high enough, $\propto=.91$.

A Descriptive Statistic test was conducted to find out the mean score of encountering the 33 challenges of the 50 participants. The result was reported below in Table 5. From the table, it can be seen that the participants' frequency level of encountering challenges in maximizing classroom interaction was slightly below $3.5(\mathrm{M}=3.32)$. A One Sample T-test was run to compare the mean score $(\mathrm{M}=3.32)$ to the test value of 3.5. The result shows that the mean score $(M=3.32)$ is not different from the test value of $3.5(t=-2.84, p=.01)$. It is obvious that the participants' frequency level of countering challenges in maximizing classroom interaction was at a high level. It could be concluded that the 50 participants quite often encountered the challenges in maximizing classroom interaction.

Table 5. Participants' Frequency of Encountering Challenges in Maximizing Classroom Interaction

\begin{tabular}{llllll}
\hline Variable & $\mathrm{N}$ & Min. & Max. & Mean & SD \\
\hline Frequency & 50 & 2.39 & 4.18 & 3.32 & .46 \\
\hline
\end{tabular}

4.2 Participants' Frequency of Encountering Challenges in Maximizing Classroom Interaction Caused by Physical Factors or Learning Conditions

Table 6 below presents the frequency of encountering challenges in maximizing classroom interaction related to physical factors or learning conditions of the fifty EFL teachers participating in the research. The data includes all 50 participants' responses about their frequency of encountering the 10 challenges in the first cluster.

A Descriptive Statistic test was conducted to find out the 50 participants' frequency level of encountering challenges in maximizing classroom interaction caused by physical factors or learning conditions. The result was reported below in Table 6. From the table, it can be seen that the participants' frequency level of encountering challenges in first cluster is slightly below level $3.5(\mathrm{M}=$ 3.34). The mean score $(M=3.34)$ was then compared with the test value of 3.5 by conducting a one sample t-test. The result shows that the mean score of 3.34 is the same as the test value $3.5(t=-2.36, p$ $=.02)$. It is obvious that the mean score of the frequency of encountering challenges in maximizing classroom interaction related to physical factors or learning conditions is quite frequent. It could be concluded that the participants quite frequently encountered the challenges in maximizing classroom interaction related to physical factors or learning conditions. 
Table 6. Participants' Frequency of Encountering Challenges in Maximizing Classroom Interaction Caused by Physical Factors or Learning Conditions

\begin{tabular}{llllll}
\hline Variable & $\mathrm{N}$ & Min. & Max. & Mean & SD \\
\hline Frequency of challenges in learning conditions & 50 & 2.30 & 4.30 & 3.34 & .48 \\
\hline
\end{tabular}

4.3 Participants' Frequency of Encountering Challenges in Maximizing Classroom Interaction Caused by Learner's Factors

Table 7 below presents the fifty participants' frequency of encountering challenges in maximizing classroom interaction caused by learner-related factors. The data includes all 50 participants' responses about their frequency of encountering the 12 challenges in the second cluster.

A Descriptive Statistic test was run to find out the frequency of encountering challenges in maximizing classroom interaction related to learners' traits of the fifty EFL teachers participating in the research. The result was reported below in Table 7. From Table 7, it could be seen that the frequency level of encountering challenges in maximizing classroom interaction related to learners' traits $(\mathrm{M}=3.58)$ was slightly higher than 3.5. It could be concluded that the participants quite often encountered the challenges in maximizing classroom interaction caused by learner-related factors $(\mathrm{M}=3.58, \mathrm{SD}=.49)$.

Table 7. Participants' Frequency of Encountering Challenges in Maximizing Classroom Interaction Caused by Learner-Related Factors (Cluster 2)

\begin{tabular}{llllll}
\hline Variable & $\mathrm{N}$ & Min. & Max. & Mean & SD \\
\hline Frequency of challenges in learner-related factors & 50 & 2.25 & 4.50 & 3.58 & .49 \\
\hline
\end{tabular}

4.4 The Frequency of Encountering Challenges in Maximizing Classroom Interaction Caused by Teacher's Factors

Table 8 below presents the fifty participants' frequency of encountering challenges in maximizing classroom interaction caused by teacher-related factors. The data includes all 50 participants' responses about their frequency of encountering the 11 challenges in the third cluster.

A Descriptive Statistic test was run to find out the 50 participants' frequency of encountering challenges in maximizing classroom interaction caused by teacher-related factors. The result was reported below in Table 8. From Table 8, it could be seen that the 50 participants' frequency level of encountering challenges in maximizing classroom interaction caused by teacher-related factors $(\mathrm{M}=$ 3.01) was just slightly higher than 3.00. A One Sample T-test was conducted to compare the mean score $M=3.01$ with the test value of 3.00. The result shows that the mean score $M=3.01$ is equivalent to the test value of $3.00(t=.17, p=.87)$. It could be concluded that the participants sometimes encountered the challenges in maximizing classroom interaction caused by teacher-related factors. 
Table 8. Participants' Frequency of Encountering Challenges in Maximizing Classroom Interaction Caused by Teacher-Related Factors

\begin{tabular}{llllll}
\hline Variable & $\mathrm{N}$ & Min. & Max. & Mean & SD \\
\hline Frequency of challenges in teacher-related factors & 50 & 1.91 & 4.00 & 3.01 & .53 \\
\hline
\end{tabular}

\subsection{The Challenges in Maximizing Classroom Interaction with the Highest Encountering Frequency}

In order to examine which group of challenges in maximizing classroom interaction was most frequently encountered, the researcher of the present study compared the mean scores of all the three groups of challenges being examined $\left(\mathrm{M}_{\mathrm{A}}=3.34, \mathrm{M}_{\mathrm{B}}=3.58, \mathrm{M}_{\mathrm{C}}=3.01\right)$ respectively. Among the three mean scores, it is obvious that the mean score of the frequency of encountering challenges in maximizing classroom interaction related to teachers' traits was the lowest one $\left(\mathrm{M}_{\mathrm{C}}=3.01\right)$. Therefore, the researcher decided to check the difference between the rest two higher mean scores: the mean score of the frequency of encountering challenges in maximizing classroom interaction related to physical factors or learning conditions $\left(\mathrm{M}_{\mathrm{A}}=3.34\right)$ and the mean scorer of the frequency of encountering challenges in maximizing classroom interaction caused by learner-related factors $\left(\mathrm{M}_{\mathrm{B}}=3.58\right)$.

A Paired-Sample T-test was conducted to check the difference between the frequency of encountering challenges in maximizing classroom interaction related to physical factors or learning conditions and the frequency of encountering challenges in maximizing classroom interaction caused by learner-related factors $\left(\mathrm{M}_{\mathrm{A}}=3.34, \mathrm{M}_{\mathrm{B}}=3.58\right)$. The results were reported below in Table 9. From Table 9, the frequency of encountering challenges in maximizing classroom interaction related to physical factors or learning conditions was definitely different from the frequency of encountering challenges in maximizing classroom interaction related to learners' traits of the fifty participants ( $t=-5.05, d f=49, p$ $=.00)$. The results show that the frequency of encountering challenges in maximizing classroom interaction related to learners' traits was at higher level than the frequency of encountering challenges in maximizing classroom interaction related to learning materials and learning facilities. It could be concluded that the group of challenges in maximizing classroom interaction related to learners' traits was the most frequently encountered by the fifty EFL teachers participating in the present research $\left(\mathrm{M}_{\mathrm{B}}\right.$ $=3.58$ ).

The results of this study are in line with those by Lucha and Berhana (2015) and Suryati (2015). As presented in the section of literature review, even opportunities for students to participate in meaningful communication are sufficiently provided so as to facilitate input to become output (Brown, 2001; Ellis, 2005), learner variables such as language proficiency or cultural background (Tsui, 2001; Smith, 1992; Berdine, 1986) show to play a significant part in making classroom interaction more challenging to EFL teachers as found in this study. 


\section{Conclusions}

This study aims to obtain more insights into EFL challenges in maximizing classroom interaction. From the research results and discussions, the researcher could draw out some conclusions below:

Firstly, the participants of the research quite frequently encountered the challenges in maximizing classroom interaction caused by different factors including physical factors, learner-related factor and teacher-related factors.

Besides, no significant difference in the frequency of encountering challenges in maximizing classroom interaction due to participants' different background features could be concluded. It was the unbalance between the numbers of participants corresponding to each group of similar background features that causes a big difficulty for the researcher to draw out any conclusions on the difference in the frequency of encountering the challenges due to the respondents' background features. The similar frequency level of encountering challenges in maximizing classroom interaction among the EFL teachers surveyed may result from the similarity in learners' learning culture and learning conditions in Mekong Delta.

Finally, the results show that the participants most frequently encountered the challenges caused by learner-related factors. It could be the one-dimensional data from the EFL teachers that reveals the highest frequency of encountering challenges due to learner-related factors. The EFL teachers surveyed tend to emphasize the challenges caused by learner-related factors although they admitted sometimes encountering some challenges caused by teacher-related factors.

With regard to the findings of this study on maximizing classroom interaction and based on the literature review on factors affecting classroom interaction and principles in language teaching and learning as well as the theory of second language acquisition, it is worth considering conducting further research on the following topics:

a) EFL learners' challenges in classroom interaction.

b) EFL teachers' perceptions towards the Effects of ICT on maximizing classroom interaction.

c) EFL learners' perceptions towards the Effects of ICT on maximizing classroom interaction.

Results from the studies on the above topics may add more evidence of contribution of ICT in language teaching and learning, especially in maximizing classroom interaction.

\section{References}

Ackroyd, S. (1992). Data collection in context. Longman Group United Kingdom.

Angelo, T. A. (1993). A Teacher's Dozen: Fourteen General, Research-based Principles for Improving Higher Learning in Our Classrooms. AAHE Bulletin, 45(8).

Berdine, R. (1986). Why some students fail to participate in class. Marketing News, 20, 2324.

Brown, H. D. (2001). Teaching by principles: An interactive approach to language pedagogy (2nd ed.). London: Longman.

Brown, J. D. (2001). Using survey in language programs. Cambridge, UK: Cambridge University 
Press.

Canh, L. (2011). Language and Vietnamese Pedagogical Contexts: How appropriate and effective are communicative language teaching methodologies in contemporary Vietnam? Retrieved from http://www.nzdl.org/gsdl/collect/literatu/index/assoc/HASH0196.dir/doc.pdf

Dictionary, O. (2005). English dictionary. Webster's New World College Dictionary.

Duy, P. N. (2014). Implimentation communicative language teaching in Vietnam. Retrieved April 12, 2014 , from https://www.sites.google.com/site/phucngoduy/myarticleandessay/essayimplementationofcommun icativelanguageteachinginvietnam

Ellis, R. (1984). Classroom Second Language Development: A Study of Classroom Interaction and Language Acquisition. Pergamon.

Ellis, R. (1991). Instructed second language acquisition: Learning in the classroom. Wiley-Blackwell.

Ellis, R. (2005). Principles of instructed language learning. System, 33(2), 209-224. https://doi.org/10.1016/j.system.2004.12.006

Fassinger, P. (1995). Understanding Classroom Interaction: Students' and Professors' Contributions to $\begin{array}{lllll}\text { Students' } & \text { Silence. } & \text { Higher } & \text { Education, } & 66(1),\end{array}$ https://doi.org/10.1080/00221546.1995.11774758

Gass, S. (1997). Input, interaction, and the development of second languages. Mahwah, NI: Lawrence Erlbaum Associates.

Hiep, P. H. (2007). Communicative language teaching: unity within diversity. ELT Journal, 61(3), 193-201. https://doi.org/10.1093/elt/ccm026

Krashen, S. D. (1985). The input hypothesis: Issues and implications. Addison-Wesley Longman Ltd.

Krashen, S.D. (1987). Principles and Practice in Second Language Acquisition. Prentice-Hall International.

Kumaravadivelu, B. (2003). Beyond methods: Macro-strategies for language teaching. Yale University Press.

Long, M. (1996). The role of the linguistic environment in second language acquisition. In W. Ritchie, \& T. Bhatia (Eds.), Handbook of second language acquisition (pp. 413-468). San Diego: Academic Press.

Lucha, Z. T., \& Berhanu, A. (2015). A study on the implementation of students' classroom oral interaction in sire secondary school EFL class: Grade 10 in focus. Science, Technology and Arts Research Journal, 4(2), 294-301. https://doi.org/10.4314/star.v4i2.41

Mackey, A. (2007). The Conversational Interaction in Second Language Acquisition. Oxford: Oxford University Press.

Ministry of Education and Training (MOET). (2008). Teaching and learning foreign languages in the national education system, period 2008-2020.

Moore, M. G. (1989). Editorial: Three types of interaction. The American Journal of Distance Published by SCHOLINK INC 
Education, 3(2), 1-6. https://doi.org/10.1080/08923648909526659

Ngan, T. (2013). Vi sao hoc muoi nam van khong noi duoc. Retrieved May 10, 2014, from http://www.vietbao.vn/Giao-duc/Ngoai-ngu-trong-nha-truong-Vi-sao-hoc-10-nam-van-khong-noiduoc/45125420/202/

Ritchie, J., \& Spencer, L. (1994). Qualitative data analysis for applied policy research: Analyzing qualitative data. London: Routledge.

Rivers, W. (1987). Interaction as the Key to Teaching Language for Communication. In a Wilga M. Rivers (Ed.), Interactive Language Teaching. Cambridge University Press. NY.

Saeed, K. M., Khaksari, M., Eng, L. S., \& Ghani, A. M. A. (2016). The role of learner-learner interaction in the development of speaking skills. Theory and Practice in Language Studies, 6(2), 235-241. https://doi.org/10.17507/tpls.0602.03

Sapsford, R., \& Jupp, V. (Eds.). (2006). Data collection and analysis. Sage.

Simpson, R. J., \& Galbo, J. J. (1986). Interaction and learning: Theorizing on the art of teaching. Interchange, 17(4), 37-51. https://doi.org/10.1007/BF01807015

Smith, D. (1992). Encouraging Students' Participation in Large Classes: A Modest Proposal. Teaching Sociology, 20(4), 337-339. https://doi.org/10.2307/1318983

Suryati, N. (2015). classroom interaction strategies employed by English teachers at lower secondary schools. TEFLIN Journal, 26(2), 247-264. https://doi.org/10.15639/teflinjournal.v26i2/247-264

Swain, M., \& Lapkin, S. (1995). Problems in Output and the Cognitive Processes They Generate: A Step Towards Second Language Learning. Applied Linguistics, 16, 371-391. https://doi.org/10.1093/applin/16.3.371

Toni, A., \& Parse, F. (2013). The status of teacher's questions and students' responses: The case of an EFL class. Journal of Language Teaching and Research, 4(3), 564-569. https://doi.org/10.4304/jltr.4.3.564-569

Tsui, A. B. (2001). Classroom interaction. The Cambridge guide to teaching English to speakers of other languages, 120-125. https://doi.org/10.1017/CBO9780511667206.018

Vrasidas, C. (2000). Constructivism versus objectivism: Implications for interaction, course design, and evaluation in distance education. International Journal of Educational Telecommunications, 6(4), 339-362.

Vrasidas, C., \& McIsaac, M. S. (1999). Factors influencing interaction in an online course. The American Journal of Distance Education, 13, 2236. https://doi.org/10.1080/08923649909527033

Vygotsky, L. (1978). Interaction between learning and development. Readings on the development of children, 23(3), 34-41. 